\title{
Kedudukan Badan Pemeriksaan Keuangan dalam Sistem Ketatanegaraan Republik Indonesia
}

\author{
Oleh: Tahegga Primananda Alfath. ${ }^{1}$
}

\begin{abstract}
Supreme Audit Agency is derived from the Raad van Rekenkamer in the days of the Dutch East Indies. The results of the audit or examination conducted an auditing firm to be deposited to the Parliament and the Council for further action. Supervisory powers to the Audit Board is not surprising that no mention coincide with supervisory functions in the House. If it is interpreted as the Audit Board is also included as an auxiliary to the functions of the House of Representatives in the field of oversight of government performance. so this is will analysis about Position the Board of Audit in the constitutional system of the Republic of Indonesia.
\end{abstract}

Keywords: authority, state organs, and constitution.

\section{A. Pendahuluan}

Reformasi pada tahun 1998 menjadi babak baru dalam perubahan format ketatanegaraan Indonesia. Ketatanegaraan Indonesia memiliki kebaharuan, khususnya terhadap hubungan antar kelembagaannya. Jika sebelum reformasi lembaga negara memiliki hirarkhi, dikenal ada lembaga negara tertinggi yang berupa Majelis Permusyawaratan Rakyat (MPR), kini kedudukan antar lembaga negara menjadi sejajar dan menganut prinsip check and balances. Hal ini untuk menghindari potensi "power absolut corrupt absolutely", hukum kemudian menjadi panglima tertinggi dalam segala kegiatan yang dilakukan oleh lembaga negara bukan lagi persoon, rule of law.

Fungsi design (penataan) dalam konstitusi erat kaitannya dengan pembagian kekuasaan. Berbicara pembagian kekuasaan pasti terpengaruh dengan ajaran Montesquieu yang terkenal dengan ajaran Trias Politica. ${ }^{2}$ Kekuasaan negara itu harus dicegah dari kekuasaan satu tangan, karena akan timbul kekuasaan yang sewenang-wenang. Oleh sebab itu kekuasaan harus dipisahkan dalam tiga macam kekuasaan (scheiding van machten) yang lazim disebut sebagai kekuasaan legislatif, kekuasaan eksekutif, dan kekuasaan yudikatif, pelaksanaan ketiga kekuasaan tersebut

\footnotetext{
${ }^{1}$ Dosen Hukum Tata Negara Fakultas Hukum Universitas Narotama Surabaya.

${ }^{2}$ Montesquieu,The Spirit of Laws: Dasar-dasar Ilmu Hukum dan Ilmu Politik, (diterjemahkan oleh M. Khoril Anam), Nusa Media, Bandung, 2011, h. 186-189. Lihat juga Montesquieu, The Spirit of The Laws, (translated and edited by Anne M. Cohler, Et. al.), The Press Syndicate of the University of Cambridge The Pitt Building, New York, USA, 1989, Book 11, Chapter 6. Lihat juga Baron de Montesquieu, I' Esprit des Lois, Garnier, Paris, 1748.
} 
perlu dibentuk badan-badan tertentu yang terpisah satu sama lain (scheiding van organen). ${ }^{3}$

Badan-badan tertentu dalam setiap cabang kekuasaan memiliki kewenangannya masing-masing. Dalam hal landasan yuridis pembentukan dan kewenangan lembaga negara di Indonesia setelah Amandemen UUD 1945 (UUD NRI 1945), Jimly Asshiddiqie membedakan menjadi 3 (tiga) kelompok, yaitu: ${ }^{4}$

a. Lembaga negara yang dibentuk berdasar perintah dari UUD NRI 1945 (constitutionally entrusted power).

b. Lembaga negara yang dibentuk berdasar perintah undang-undang (legislatively entrusted power)

c. Lembaga negara yang dibentuk berdasarkan perintah dari keputusan presiden.

Pembagian kelompok lembaga negara yang ditinjau dari landasan yuridis pembentuknya nyatanya masih menyisakan problema tersendiri untuk dapat memahami kedudukan suatu lembaga negara dalam sebuah sistem ketatanegaraan Republiik Indonesia.

Badan Pemeriksa Keuangan merupakan sebuah badan yang ada didalam sistem ketatanegaraan Indonesia sejak masih jaman Hindia Belanda. Landasan hukum pembentukannya jelas ada di dalam UUD NRI 1945 yakni dalam Pasal 23E Ayat 1 dan 2 yang memiliki kewenangan:

i. Memeriksa pengelolaan dan tanggung jawab tentang keuangan negara secara bebas dan mandiri. (Pasal 23E ayat (1))

ii. Menyerahkan hasil pemeriksaan keuangan negara kepada DPR, DPD, dan DPRD. (Pasal 23E ayat (2))

Badan pemeriksa Keuangan (BPK) ini sendiri berasal dari Raad van Rekenkamer pada zaman Hindia Belanda. Hasil audit atau pemeriksaan yang dilakukan BPK harus disetorkan kepada DPR dan DPD untuk ditindak lanjuti. Kekuasaan pengawasan pada BPK ini tidak heran jika ada yang menyebutkan berhimpitan dengan fungsi pengawasan yang ada pada DPR. Jika hal tersebut diartikan demikian maka BPK juga termasuk sebagai auxiliary terhadap fungsi DPR di bidang pengawasan terhadap kinerja pemerintahan. ${ }^{5}$

Dari penjelasan latar belakang tersebut maka dapat ditarik sebuah permasalahannya, yaitu:

1. Apa kewenangan yang dimiliki oleh Badan Pemeriksa Keuangan Republik Indonesia?

2. Apa kedudukan Badan Pemeriksa Keuangan Republik Indonesia dalam sistem ketatanegaraan Republik Indonesia?

\footnotetext{
${ }^{3}$ Moh Kusnardi dan Bintan R. Saragih, Susunan Pembagian Kekuasaan Menurut Sistem Undang-Undang Dasar 1945, Cetakan ketiga, PT Gramedia, Jakarta, 1983, h. 31.

${ }^{4}$ Jimly Asshiddiqie, Perkembangan Ketatanegaraan Pasca Perubahan UUD 1945 dan Tantangan Pembaruan Pendidikan Hukum Indonesia, Makalah disampaikan dalam seminar dan Lokakarya Nasional Perkembangan Ketatanegaraan Pasca Perubahan UUD 1945 dan Pembaruan Kurikulum Pendidikan Hukum Indonesia, Diselenggarakan Asosiasi Pengajar Hukum Tata Negara dan Hukum Adminsitrasi Negara Indonesia, di Jakarta, 7 September 2004, h. 7. Dalam Lukman Hakim, Eksistensi Komisi-Komisi Negara Dalam Sistem Ketatanegaraan Republik Indonesia, Desertasi, Universitas Brawijaya, 2009, h. 193.

${ }^{5}$ Ni'matul Huda, Lembaga Negara dalam Masa Transisi Demokrasi, UII Press, Yogyakarta, 2007, h.
} 143. 


\section{B. Pembahasan}

\section{Kewenangan yang Dimiliki oleh Badan Pemeriksa Keuangan Republik Indonesia.}

Badan Pemeriksa Keuangan, yang selanjutnya disingkat BPK, adalah lembaga negara yang bertugas untuk memeriksa pengelolaan dan tanggung jawab keuangan negara sebagaimana dimaksud dalam Undang-Undang Dasar Negara Republik Indonesia Tahun 1945. Kewenangan yang dimiliki oleh BPK dapat dilihat dalam Pasal 23E Undang-Undang Dasar Negara Republik Indonesia Tahun 1945 (UUD NRI 1945), dan pada Undang-Undang Nomor 15 Tahun 2006 tentang Badan Pemeriksa Keuangan (UU BPK). Pada penulisan ini akan mendeskripsikan tentang kewenangan yang dimiliki oleh BPK, akan tetapi sebelum membahas lebih lanjut akan dipaparkan terlebih dahulu apa yang dimaksudkan dengan kewenangan.

Istilah kewenangan yang memiliki kata dasar wewenang, diadopsi dari arti kata authority (Inggris) dan bevoegheid (Belanda). Kewenangan adalah otoritas yang dimiliki suatu lembaga untuk melakukan sesuatu atau tidak melakukan sesuatu, juga merupakan wujud nyata dari kekuaaan. Hal teresebut selaras dengan Robert Bierstedt, menjelaskan wewenang adalah institutiolainalized power, yaitu kekuasan yang dilembagakan. ${ }^{6}$

Wewenang pada pengertian authority dalam Black's Law Dictionary, dapat diartikan sebagai: ${ }^{7}$

The right or permission to act legally on another's behalf; the power of one person to affect another's legal relations by acts done in accordance with the other's manifestation of assent; the power delegated by a principal to an agent.

Menurut Philipus M. Hadjon, wewenang (bevoegheid) dideskripsikan sebagai kekuasaan hukum (rechtsmacht). Jadi dalam konsep hukum publik, wewenang berkaitan dengan kekuasaan. ${ }^{8}$ Lebih lanjut dikatakan:

Sebagai konsep hukum publik, wewenang sekurang-kurangnya terdiri atas tiga komponen, yaitu pengaruh, dasar hukum dan konformitas hukum. Komponen pengaruh adalah penggunaan wewenang dimaksudkan untuk mengendalikan perilaku subyek hukum. Komponen dasar hukum, bahwa wewenang itu selalu harus dapat ditunjuk dasar hukumnya dan komponen dasar konformitas hukum mengandung makna adanya standar wewenang, yaitu standar umum (semua jenis wewenang) dan standar khusus (untuk jenis wewenang tertentu). ${ }^{9}$

\footnotetext{
${ }^{6}$ Robert Bierstedt dalam Prof. Miriam Budiharjo, Demokrasi di Indonesia: Demokrasi Parlementer dan Demokrasi Pancasila, dalam PSHK, Semua Harus Terwakili: Studi Mengenai Reposisi MPR, DPR, dan Lembaga Kepresidenan di Indonesia, PSHK, Jakarta, 2000, h. 6.

${ }^{7}$ Black Law's Dictionary, Eds. Bryan A. Garnet et.al, West Publishing, St. Paul, 2009. H.152.

${ }^{8}$ Philipus M. Hadjons, sebagaimana dikutip Sukardi, Pembatalan Perda dan Akibat Hukumnya, Disertasi, Universitas Airlangga, 2009, h. 34.

${ }^{9}$ Ibid.
} 
Kewenangan menurut Hardjono, meliputi kewenangan antarlembaga negara yang bersifat horizontal dan kewenangan secara vertikal, yaitu berkaitan dengan penggunaan wewenang tersebut kepada rakyat. Lebih lanjut Hardjono menjelaskan bahwa sering terjadi kekaburan menggunaan istilah fungsi, tugas, wewenang, dan kewajiban. Fungsi mempunyai makkna yang lebih luas daripada tugas. Jika tugas akan digunakan, akan lebih tepat untuk menyebut aktivitasaktivitas yang diperlukan agar fungsi dapat terlaksana. Tugas selain mempunyai aspek ke dalam juga memiliki aspek ke luar. Aspek ke luar dari tugas adalah wewenang. ${ }^{10}$

Menurut Moh. Fadli, Kewenangan pasti berkaitan dengan pilar utama hukum yaitu asas legalitas. Asas legalitas merupakan salah satu prinsip utama yang dijadikan sebagai dasar legitimasi (pengakuan dan penerimaan) setiap penyelenggaraan pemerintahan dan kenegaraan disetiap negara hukum. Berdasarkan prinsip tersebut maka sumber wewenang bagi pemerintah adalah peraturan perundang-undangan. ${ }^{11}$

Lebih lanjut Moh.Fadli mengemukakan bahwa kewenangan yang bersumber dari peraturan perundang-undangan tersebut diperoleh melalui tiga cara yaitu: $^{12}$

Pertama, atribusi, adalah pemberian wewenang pemerintahan yang baru oleh suatu ketentuan dalam perundang-undangan. Atribusi di dapat dari legislator yang kompeten memberikan atribusi wewenang misalnya original legislator dan delegated legislator. Kedua, delegasi, pelimpahan suatu wewenang yang telah ada oleh badan atau jabatan tata usaha negara yang telah memperoleh wewenang pemerintahan secara atributif kepada badan atau jabatan tata usaha negara lainnya. Dan ketiga, mandat, terjadi ketika organ pemerintahan mengizinkan kewenangannya dijalankan oleh organ lain atas namanya.

Teori kewenangan yang telah dipaparkan diatas, memberikan sebuah gambaran tentang cara pandang menentukan kewenangan yang dimiliki oleh BPK. Kewenangan yang dimiliki oleh BPK merupakan kewenangan yang bersumber langsung dari UUD NRI 1945 melalui atribusi, sehingga lembaga ini termasuk dari salah satu lembaga negara yang kewenangannya diberikan oleh UUD NRI 1945 (constitutionally entrusted power).

Kewenangan BPK iatur dalam Pasal 23E UUD NRI 1945 yang dinyatakan sebagai berikut:

(1) Untuk memeriksa pengelolaan dan tanggung jawab tentang keuangan negara diadakan satu Badan Pemeriksa Keuangan yang bebas dan mandiri.

(2) Hasil pemeriksaan keuangan negara diserahkan kepada Dewan Perwakilan Rakyat, Dewan Perwakilan Daerah, dan Dewan Perwakilan Rakyat Daerah, sesuai dengan kewenangannya.

\footnotetext{
${ }^{10}$ Hardjono, sebagaimana dikutip Firmansyah Arifin, et. al., Hukum dan Kuasa Konstitusi, KRHN, Jakarta, 2004, h. 27-28.

${ }^{11}$ Moh Fadli, jazim Hamidi, dan Mustafa Lutfi, Pembentukan Peraturan Desa Partisipatif (Head To A Good Village Governance), Cetakan pertama, UB Press, Malang, 2011, h. 99.

${ }^{12}$ Ibid. h. 100.
} 
(3) Hasil pemeriksaan tersebut ditindaklanjuti oleh lembaga perwakilan dan/atau badan sesuai dengan undang-undang.

Kewenangan BPK dalam menjalankan tugasnya ditentukan dalam Pasal 9angka (1) UU BPK, yang dinyatakan sebagai berikut:

a. menentukan objek pemeriksaan, merencanakan dan melaksanakan pemeriksaan, menentukan waktu dan metode pemeriksaan serta menyusun dan menyajikan laporan pemeriksaan;

b. meminta keterangan dan/atau dokumen yang wajib diberikan oleh setiap orang, unit organisasi Pemerintah Pusat, Pemerintah Daerah, Lembaga Negara lainnya, Bank Indonesia, Badan Usaha Milik Negara, Badan Layanan Umum, Badan Usaha Milik Daerah, dan lembaga atau badan lain yang mengelola keuangan negara;

c. melakukan pemeriksaan di tempat penyimpanan uang dan barang milik negara, di tempat pelaksanaan kegiatan, pembukuan dan tata usaha keuangan negara, serta pemeriksaan terhadap perhitunganperhitungan, surat-surat, bukti-bukti, rekening koran, pertanggungjawaban, dan daftar lainnya yang berkaitan dengan pengelolaan keuangan negara;

d. menetapkan jenis dokumen, data, serta informasi mengenai pengelolaan dan tanggung jawab keuangan negara yang wajib disampaikan kepada BPK;

e. menetapkan standar pemeriksaan keuangan negara setelah konsultasi dengan Pemerintah Pusat/Pemerintah Daerah yang wajib digunakan dalam pemeriksaan pengelolaan dan tanggung jawab keuangan negara;

f. menetapkan kode etik pemeriksaan pengelolaan dan tanggung jawab keuangan negara;

g. menggunakan tenaga ahli dan/atau tenaga pemeriksa di luar BPK yang bekerja untuk dan atas nama BPK;

h. membina jabatan fungsional Pemeriksa;

i. memberi pertimbangan atas Standar Akuntansi Pemerintahan; dan

j. memberi pertimbangan atas rancangan sistem pengendalian intern

k. Pemerintah Pusat/Pemerintah Daerah sebelum ditetapkan oleh Pemerintah Pusat/Pemerintah Daerah.

Dalam Pasal 10 UU BPK, angka (1) BPK juga berwenang menilai dan/ atau menetapkan jumlah kerugian negara yang diakibatkan oleh perbuatan melawan hukum baik sengaja maupun lalai yang dilakukan oleh bendahara, pengelola BUMN/BUMD, dan lembaga atau badan lain yang menyelenggarakan pengelolaan keuangan negara. Pada angka (3) BPK berwenang memantau penyelesaian ganti kerugian negara/ daerah, pelaksanaan pengenaan ganti kerugian negara/daerah kepada Bendahara, pengelola BUMN/ BUMD, dan lembaga lain yang mengelola keuangan negara yang telah ditatapkan oleh BPK, dan pelaksanaan pengenaan ganti kerugian negara/ daerah yang ditetapkan berdasarkan putusan pengadilan yang telah mempunyai kekuatan hukum tetap.

Dalam Pasal 11 UU BPK, wewenang dapat pertama, memberikan pendapat kepada DPR, DPD, DPRD, Pemerintah Pusat/ Pemerintah Daerah, Lembaga Negara Lain, Bank Indonesia, Badan Usaha Milik Negara, Badan Layanan 
Umum, Badan Usaha Milik Daerah, Yayasan, dan lembaga atau badan lain, yang diperlukan karena sifat pekerjaannya.Kedua, memeberikan pertimbangan atas penyelesaian kerugian negara/daerah yang ditetapkan oleh Pemerintah Pusat/ Pemerintah Daerah, dan atau Ketiga, memberikan keterangan ahli dalam proses peradilan mengenai kerugian negara/ daerah.

Berdasarkan Pasal 23E UUD NRI 1945 objek pemeriksaan yang dilakukan oleh BPK adalah keuangan negara, apa saja yang kemudian menjadi kategori keuangan negara dapat dilihat secara penafsiran sistematis pada Pasal 2 UndangUndang Nomor 17 Tahun 2003 tentang Keuangan Negara (UU Keuangan Negara), yaitu:

a. hak negara untuk memungut pajak, mengeluarkan dan mengedarkan uang, dan melakukan pinjaman;

b. kewajiban negara untuk menyelenggarakan tugas layanan umum pemerintahan negara dan membayar tagihan pihak ketiga;

c. Penerimaan Negara;

d. Pengeluaran Negara;

e. Penerimaan Daerah;

f. Pengeluaran Daerah;

g. kekayaan negara/kekayaan daerah yang dikelola sendiri atau oleh pihak lain berupa uang, surat berharga, piutang, barang, serta hak-hak lain yang dapat dinilai dengan uang, termasuk kekayaan yang dipisahkan pada perusahaan negara/ perusahaan daerah;

h. kekayaan pihak lain yang dikuasai oleh pemerintah dalam rangka penyelenggaraan tugas pemerintahan dan/atau kepentingan umum;

i. kekayaan pihak lain yang diperoleh dengan menggunakan fasilitas yang diberikan pemerintah. (Kekayaan pihak lain sebagaimana dimaksud dalam huruf I ini meliputi kekayaan yang dikelola oleh orang atau badan lain berdasarkan kebijakan pemerintah, yayasan-yayasan di lingkungan kementerian negara/lembaga, atau perusahaan negara/daerah.)

Menurut Ni'matul Huda, kepada BPK diberi kewenangan untuk melakukan 3 (tiga) jenis pengawasan, yakni:

a. Pemeriksaan keuangan, adalah pemeriksaan atas laporan keuangan pemerintahan pusat dan pemerintahan daerah.

b. Pemeriksaan kinerja, adalah pemeriksaan atas aspek ekonomi dan efesiensi, serta pemeriksaan atas aspek efektivitas yang lazim dilakukan bagi kepentingan manajemen oleh aparat pengawasan intern pemerintah.

c. Pemeriksaan dengan tujuan tertentu, adalah pemeriksaan yang dilakukan dengan tujuan khusus, diluar pemeriksaan keuangan dan pemeriksaan kinerja.

BPK memiliki kebebasan dan kemandirian dalam ketiga tahap pemeriksaan, yakni perencanaan, pelaksanaan, dan tahap perencanaan mencakup kebebasan dalam menentukan objek yang akan diperiksa, kecuali pemeriksaan yang objeknya diatur tersendiri dalam undang-undang, atau pemeriksaan berdasarkan permintaan khusus dari lembaga perwakilan. 


\section{Kedudukan Badan Pemeriksa Keuangan dalam Sistem Ketatanegaraan Republik Indonesia.}

Kedudukan BPK dalam sistem ketatanegaraan Republik Indonesia jika dilihat dari kewenangan yang diberikan langsung oleh UUD NRI 1945 maka lembaga negara ini tergolong sebagai Lembaga Negara Yang Kewenangannya Diberikan oleh UUD NRI 1945 (constitutionally entrusted power).Pendapat Sri Soemantri yang menyatakan dalam UUD NRI 1945 ada delapan yang dapat disebut sebagai lembaga negara. Kedelapan itu terdiri dari BPK, DPR, DPD, MPR, Presiden dan Wakil Presiden, MA, MK, dan KY. Pendapat tersebut didasarkan pemikiran sistem kelembagaan negara dalam UUD NRI 1945 dibagi menjadi tiga bidang/ fungsi. Pertama, dalam bidang perundang-undangan. Kedua, berkaiatan dengan pengawasan. Dan Ketiga berkaitan dengan pengangkatan hakim agung. ${ }^{13}$

Harjono juga menyatakan, UUD NRI 1945 telah menganut sistem distribusi kewenangan lembaga negara secara fungsional (functionally distributed system), dengan menetapkan fungsi-fungsi tertentu yang diperlukan untuk menyelenggarakan ketatanegaraan. Fungsi-fungsi tersebut adalah: (i) penetapan dan pengubahan undang-undang dasar (dijalankan oleh MPR); (ii) pembuat undang-undang (dijalankan oleh DPR); (iii) pelaksanaan pemerintah (dijalankan oleh Presiden dan Wakil Presiden); (iv) pelaksana peradilan (dilaksanakan oleh MA dan MK); (iv) fungsi lain untuk meningkatkan kualitas penyelenggaraan pemerintahan agar tercipta good corporate governance (dilaksanakn oleh KPU, Komisi Yudisial, dan lembaga constitutional importance lainnya). ${ }^{14}$

Dalam hal landasan yuridis pembentukan dan kewenangan lembaga negara di Indonesia setelah Amandemen UUD 1945, Jimly Asshiddiqie membedakan menjadi 3 (tiga) kelompok, yaitu: ${ }^{15}$

a. Lembaga negara yang dibentuk berdasar perintah dari UUD NRI 1945 (constitutionally entrusted power).

b. Lembaga negara yang dibentuk berdasar perintah undang-undang (legislatively entrusted power)

c. Lembaga negara yang dibentuk berdasarkan perintah dari keputusan presiden.

\footnotetext{
${ }^{13}$ Firmansyah Arifin, dkk, Lembaga Negara dan Sengketa Kewenangan Antarlembaga Negara, Konsorsium Reformasi Hukum Nasional bekerjasama dengan Mahkamah Konstitusi Republik Indonesia, didukung oleh The Asia Foundation dan USAID, Jakarta, 2005, h. 36.

${ }^{14}$ Harjono, “Lembaga Negara dalam UUD 1945”, Jurnal Konstitusi Volume 4 Nomor 2, Juni 2007, h. 14. Lihat juga dalam Gunawan A. Tauda, Komisi Negara Independen: Eksistensi Independent Agencies Sebagai Cabang Kekuasaan Baru dalam Sistem Ketatanegaraan, Cetakan Pertama, Genta Press, Yogyakarta, 2012, h. 150.
}

\footnotetext{
${ }^{15}$ Jimly Asshiddiqie, Perkembangan Ketatanegaraan Pasca Perubahan UUD 1945 dan Tantangan Pembaruan Pendidikan Hukum Indonesia, Makalah disampaikan dalam seminar dan Lokakarya Nasional Perkembangan Ketatanegaraan Pasca Perubahan UUD 1945 dan Pembaruan Kurikulum Pendidikan Hukum Indonesia, Diselenggarakan Asosiasi Pengajar Hukum Tata Negara dan Hukum Adminsitrasi Negara Indonesia, di Jakarta, 7 September 2004, h. 7. Dalam Lukman Hakim, Eksistensi Komisi-Komisi Negara Dalam Sistem Ketatanegaraan Republik Indonesia, Desertasi, Universitas Brawijaya, 2009, h. 193.
} 
Sejarah adanya BPK merupakan kelanjutan dari Alegemene Reken Kamer pada masa Hindia Belanda. Badan ini semula adalah alat eksekutif dengan tugas mengurus pembukuan. Badan itu pertama kali di Hindia Belanda didirikan oleh Herman William Deandles dengan nama "Generalle Raken Kamer", kemudian dengan ditetapkannya Indische Comtabilitaitswet pada Tahun 1864, Parlemen Belanda mendirikan Algemene Reken Kamer yang terlepas dari pengaruh kekuasaan eksekutif.Hal tersebut dapat ditelusuri secara historis dalam perkataan Soepomo dalam Rapat Besar Panitia Persiapan Kemerdekaan Indonesia Tanggal 18 Agustus 1945, mengatakan: "..., dan ada lagi suatu badan keuangan (rekenkamer) yang mengontrol keuangan negara seperti biasa" (ejaan sudah disesuaikan dengan saat ini). ${ }^{16}$

Alegemene Reken Kamer atau yang saat ini dinamai dengan Badan Pemeriksa Keuangan (BPK), ditinjau dari segi fungsinya adalah melaksanakan salah satu bidang pengawasan yang dilakukan oleh DPR, DPD, dan DPRD (lembaga perwakilan rakyat). Hal tersebut dapat dicermati dalam klausul Pasal 23E ayat (2) UUD NRI 1945, bahwa hasil pemeriksaan keuangan negara diserahkan kepada DPR, DPD, dan DPRD. Dari klausul tersebut menyiratkan bahwa ada kaitan erat dalam hubungan fungsional antara BPK dan lembaga perwakilan rakyat.

Ditinjau dari kedudukan BPK sebagai main state organdalam arti merupakan lembaga negara yang bersifat bebas dan mandiri, maka seyogyanya hasil pemeriksaan keuangan negara diserahkan kepada DPR, DPD, dan DPRD karena akan menimbulkan conlict of interest. Letak konflik tersebut akan muncul jika yang diperiksa adalah DPR, DPD, dan DPRD sendiri. Apapun hasil pemeriksaan oleh BPK, penindakannya tergantung kepada DPR. Sehingga berkaitan ini sangat dibutuhkan suatu mekanisme yang efektif agar hasil pemeriksaan dari BPK tentang keuangan negara tidak sia-sia dan tepat sasaran.

Perlu perumusan kembali bagaimana hubungan yang tepat antara DPR, DPD, DPRD, dan BPK agar tetap menjalankan fungsinya sebagai lembaga negara seusai dengan prinsip check and balances. Prinsip Check and Balances itu sendiri, menurut Black's Law Dictionary, memiliki arti "arrangement of governmental powers whereby powers of one governmental branch check or balance those of other branches." ${ }^{17}$ yakni suatu aturan antar kekuasaan pemerintahan, yang mana setiap cabang kekuasaan pemerintahan tersebut memeriksa dan mengimbangkan cabang yang lainnya. Hal tersebut merupakan prinsip dari sebuah negara demokrasi dan negara hukum modern. ${ }^{18}$

\footnotetext{
${ }^{16}$ Tahegga Primananda Alfath, Penyelesaian Sengketa Kewenangan Lembaga Negara yang Kewenangannya diberikan oleh Undang-Undang, Univeristas Airlangga, 2013.

${ }^{17}$ Hanry Campbell Black, Black's Law Dictionary: Definition of the Terms and Phrases of American and English Jurisprudence, Ancient and Modern, Sixth Edition, West Publishing Co., ST. Paul, 1990

${ }^{18}$ Titik Triwulan Tutik, Membangun Harmonisasi Kedudukan dan Fungsi Antara DPD dengan DPR Dalam Rangka Pelaksanaan Fungsi Check and Balances Pada Lembaga Perwakilan Rakyat dalam Sistem Bikameral, Makalah disajikan Pada Konferensi dan Dialog Nasional Dalam Rangka Satu Dasawarsa Amandemen UUD 1945 “Negara Hukum Indonesia, Kemana Akan Melangkah?", Jakarta, 9-10 Oktober 2012, h. 1. Lihat juga Martha Pigome, Implementasi Prinsip Demokrasi dan Nomokrasi dalam Struktur Ketatanegaraan RI Pasca Amandemen UUD 1945, Jurnal Dinamika Hukum, Volume 11, No. 2, 2011, h. 324.
} 
Lebih lanjut pengertian check and balances dari pendapat Berman, mengatakan bahwa:

"check and balances are the constitutional controls whereby separate branches of goverment have limiting powers over each others so that no branch will become supreme." (check and balances adalah kontrol konstitusional yang dimana pada setiap pembagian cabang (kekuasaan) pada pemerintahan membatasi kekuasaan satu dengan yang lainnya, jadi tidak ada cabang (kekuasaan) yang dapat menjadi paling tinggi.)

Kalimat 'no branch will become supreme'menunjukkan bahwa tidak ada cabang (kekuasaan) yang dapat menjadi lebih tinggi (supreme).

Check and balances yang muncul di dalam UUD NRI 1945 ingin meletakkan keseimbangan antar cabang kekuasaan negara, hubungan tersebut ditata sedemikian rupa sehingga tidak terjadi pemusatan kekuasaan pada salah satu cabang kekuasaan negara. Check and balances apabila dilihat dari fungsi dan tujuan yang ingin dicapai, akan mampu menciptakan pemerintahan yang demokratis dan bersih. Hal tersebut dikarenakan tidak adanya kekuasaan yang dominan utama, semua seimbang sesuai dengan kewenangannya masing-masing. Akan tetapi hal tersebut akan berarti sebaliknya jika sistem ketatanegaraan, khususnya kelembagaan (institutional separation), belum mapan untuk menata pola hubungan yang berkaitan dengan kewenangan pada tiap-tiap lembaga negara.

\section{Penutup}

1. Kesimpulan

a. Kewenangan yang dimiliki oleh Badan Pemeriksaan Keuangan Republik Indonesia adalah memeriksa pengelolaan dan tanggung jawab keuangan negara seperti yang diamanatkan dalam Pasal 23E Undang-Undang Dasar Negara Republik Indonesia Tahun 1945 dan Undang-Undang Nomor 15 Tahun 2006 tentang Badan Pemeriksa Keuangan.

b. Kedudukan Badan Pemeriksa Keuangan Republik Indonesia dalam system ketatanegaraan merupakan lembaga negara yang kewenangannya diberikan oleh Undang-Undang Dasar Negara Republik Indonesia Tahun 1945 (constitutionally entrusted power) sehingga dapat dikatan sebagai main state organ atau lembaga negara utama.

2. Saran

a. Seyogyanya perlu dirumuskan suatu mekanisme yang efektif agar hasil pemeriksaan oleh Badan Pemeriksa Keuangan bermanfaat.

b. Seyogyanya perlu dilakukan pengkajian tentang kedudukan antara BPK dengan lembaga perwakilan rakyat, sehingga tak seolah BPK hanya merupakan alat atau kepanjangan tangan dari lembaga perwakilan rakyat 


\section{Daftar Pustaka}

Montesquieu, The Spirit of Laws: Dasar-dasar Ilmu Hukum dan Ilmu Politik, (diterjemahkan oleh M. Khoril Anam), Nusa Media, Bandung, 2011.

Montesquieu, The Spirit of The Laws, (translated and edited by Anne M. Cohler, Et. al.), The Press Syndicate of the University of Cambridge The Pitt Building, New York, USA, 1989.

Baron de Montesquieu, I' Esprit des Lois, Garnier, Paris, 1748.

Moh Kusnardi dan Bintan R. Saragih, Susunan Pembagian Kekuasaan Menurut Sistem Undang-Undang Dasar 1945, Cetakan ketiga, PT Gramedia, Jakarta, 1983.

Jimly Asshiddiqie, Perkembangan Ketatanegaraan Pasca Perubahan UUD 1945 dan Tantangan Pembaruan Pendidikan Hukum Indonesia,Jakarta, 2004.

Lukman Hakim, Eksistensi Komisi-Komisi Negara Dalam Sistem Ketatanegaraan Republik Indonesia, Desertasi, Universitas Brawijaya, 2009.

Ni'matul Huda, Lembaga Negara dalam Masa Transisi Demokrasi, UII Press, Yogyakarta, 2007.

Robert Bierstedt dalam Prof. Miriam Budiharjo, Demokrasi di Indonesia: Demokrasi Parlementer dan Demokrasi Pancasila, dalam PSHK, Semua Harus Terwakili: Studi Mengenai Reposisi MPR, DPR, dan Lembaga Kepresidenan di Indonesia, PSHK, Jakarta, 2000.

Black Law's Dictionary, Eds. Bryan A. Garnet et.al, West Publishing, St. Paul, 2009.

Philipus M. Hadjons, sebagaimana dikutip Sukardi, Pembatalan Perda dan Akibat Hukumnya, Disertasi, Universitas Airlangga, 2009.

Firmansyah Arifin, et. al., Hukum dan Kuasa Konstitusi, KRHN, Jakarta, 2004.

Moh Fadli, Jazim Hamidi, dan Mustafa Lutfi, Pembentukan Peraturan Desa Partisipatif (Head To A Good Village Governance), Cetakan pertama, UB Press, Malang, 2011.

Firmansyah Arifin, dkk, Lembaga Negara dan Sengketa Kewenangan Antarlembaga Negara, Konsorsium Reformasi Hukum Nasional bekerjasama dengan Mahkamah Konstitusi Republik Indonesia, didukung oleh The Asia Foundation dan USAID, Jakarta, 2005.

Harjono, "Lembaga Negara dalam UUD 1945", Jurnal Konstitusi Volume 4 Nomor 2, Juni 2007. 
Gunawan A. Tauda, Komisi Negara Independen: Eksistensi Independent Agencies Sebagai Cabang Kekuasaan Baru dalam Sistem Ketatanegaraan, Cetakan Pertama, Genta Press, Yogyakarta, 2012.

Tahegga Primananda Alfath, Penyelesaian Sengketa Kewenangan Lembaga Negara yang Kewenangannya diberikan oleh Undang-Undang, Univeristas Airlangga, 2013.

Hanry Campbell Black, Black's Law Dictionary: Definition of the Terms and Phrases of American and English Jurisprudence, Ancient and Modern, Sixth Edition, West Publishing Co., ST. Paul, 1990

Martha Pigome, Implementasi Prinsip Demokrasi dan Nomokrasi dalam Struktur Ketatanegaraan RI Pasca Amandemen UUD 1945, Jurnal Dinamika Hukum, Volume 11, No. 2, 2011. 